\title{
Inevitable Scars; A Study on Traumatic Verbal, Emotional and Physical Abuse Distressing Females
}

\section{Syeda Farah Batool, Shamoon Noushad, Maria Alataf \& Sadaf Ahmed}

1. Psychophysiology Research lab, University of Karachi

2. Advance Educational Institute and Research Centre

\section{Abstract}

Women, a name that embraces love respect and honor but unfortunately in the setup of our society it is not applicable as Islam is deliberately pulverized and entwined by socio cultural norms and personal beliefs. The aim of this study was to identify the common psycho-social perspectives among victims exposed such insults in relation with psychosocial correlates. A general survey based study was conducted and females with the age range of 18 to 50 years were interviewed on a predesigned questionnaire with analysis of variables like stress, type of abuse, age of victimization and painful memories. The results were calculated using SPSS VERSION 20. 50\% of total respondents has reported Emotional abuse, $24 \%$ has reported sexual assault while $25 \%$ of them has reported domestic violence. There might be several reasons behind this ill practice in society from socio cultural barrier to mal practice of religious domains. These variables of abuse are not only the mere threats to psychological wellbeing of victims but also have an indirect effect on their prime roles in society as a suppressed entity. Studies have revealed that the causes of exploitation physical or mental from men to women are generally Obedience from the women, Outrage of frustration, Inferiority complex, Psychological disorder, Un-controllable sex desire \& Superiority syndrome.

Keywords

Psycho-social perspectives, Exploitation, Frustration, Inferiority complex, Emotional abuse

\section{Introduction}

Women a name that embraces love respect and honor, but unfortunately in the setup of our society it is not applicable as Islam is deliberately pulverized and entwined by socio cultural norms and personal beliefs (Norman, R. E., et al, 2012). Verbal, emotional and physical abuse has now become the most common way to steal the privilege from a female with strong connection with her wellbeing. And a girl is not allowed to raise her voice against these nuisances. Most of these problems have an origin of our cultural perspectives and personal beliefs, where a girl is not allowed to raise her voice after getting distressed by such nuisance but to get suppressed or hide such complaints. Studies have revealed that the causes of abasements physical or mental from men to women are generally; Obedience from the women, Outrage of frustration, Inferiority complex, Psychological disorder, Uncontrollable sex desire, Superiority syndrome. All these and many other factors like this counts a lot for the exploitation of women (Schumacher, J. A et al, 2001). These variables of abuse are not only the mere threats of psychological wellbeing of the victims but also have an indirect effect on their prime roles in the society as a suppressed entity. Trauma is basically an emotional or physical response of an individual in a particular situation which differs according to the individual's behavior. Losing control on our physical or environmental strains might trigger the traumatic conditions. Most of the people respond differently to the traumatic condition 
(Hogan et al., 2014). For instance; two sisters in similar conditions are confronting the trauma of their father's death but responses of both the girls in this particular situation are different, one girl cried out loud on contrary to that other girl gets silent weirdly. As the mechanisms understood human body's mechanism is designed in such a way that it deals differently with divergent situations of external and internal environment. In human's Parasympathetic nervous system (PNS) and sympathetic nervous system (SNS) play a major role in adjusting the body systems. PNS controls conditions in rest and digest mode whereas SNS is responsible for inducing quick response towards stress. SNS has been observed in working with two different ways; the fast response by releasing catecholamine within seconds and a bit slower response by activating HPA-axis that releases glucocorticoids i.e. Cortisol (W. Miller et al., 2014). Traumatic stress may also influence the life consequences in an individual's lifestyle. The continuous stimuli of stress can lead to sleeplessness (Chris Woolston et al., 2012). The reason behind this is the continuous stimulation of HPAaxis. Stress can also make a person to suffer from the loss of memory. This is because the unceasing stress stimulation may atrophy the hippocampus (Cheryl D. conard, 2008). Hippocampus is a part of limbic system and it is responsible for the conversion of STM (short term memory) into LTM (long term memory). So the individual with PTSDs may suffer from forgetfulness. The aim of this study was to identify the common psychosocial perspectives among victims exposed such insults in relation with psychosocial correlates.
Methodology

A Cross -sectional study was conducted with the adult males and females of age 18-50 years with

Exclusion Criteria of Individuals below the age 18 and Inclusion Criteria of Individuals who had ever suffered from a traumatic event. Subjects were interviewed through a pre-structured questionnaire after their permission via a consent form. This questionnaire enquired about the; Factors that influence severity of trauma, History behind trauma, how this event brought changes in individual's life. Along with the questionnaire SSS (Sadaf Stress Scale) is also used to evaluate the intensity of trauma in the subject Results were analyzed by using excel and SPSS version 20.

\section{Results}

The results when observed for the types of abuses, the results of this study showed that $25 \%$ women were facing domestic violence, with $23.40 \%$ showed sexual abuse and $50 \%$ emotional abuse. The symptoms of emotional stress showed most of the women were observed to be agitated with $55 \%$ women were facing irritability, $52 \%$ with constant worrying and $47 \%$ with sense of loneliness. $46 \%$ women were having the consequences of memory loss and relationship conflicts with $44 \%$ faced sadness. The traumatic stress was observed with a raise in mental and physical discomfort with $55 \%, 53 \%$ women avoided discussion, only $33 \%$ were having a feeling of disconnection with others, whereas, $38 \%$ women were having no expressions for emotions. 


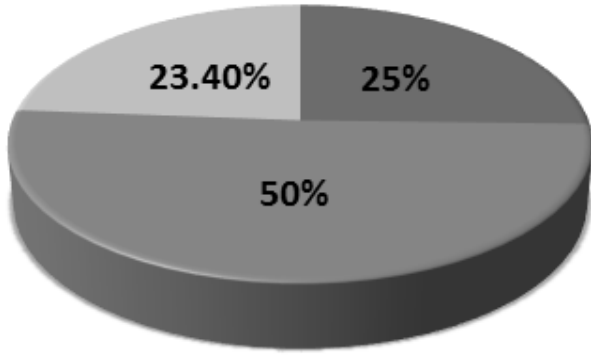

$\square$ DOMESTIC

VIOLENCE

$\square$ EMOTIONAL

ABUSE

$\square$ SEXUAL ABUSE

Figure 1.1: Type of Abuse

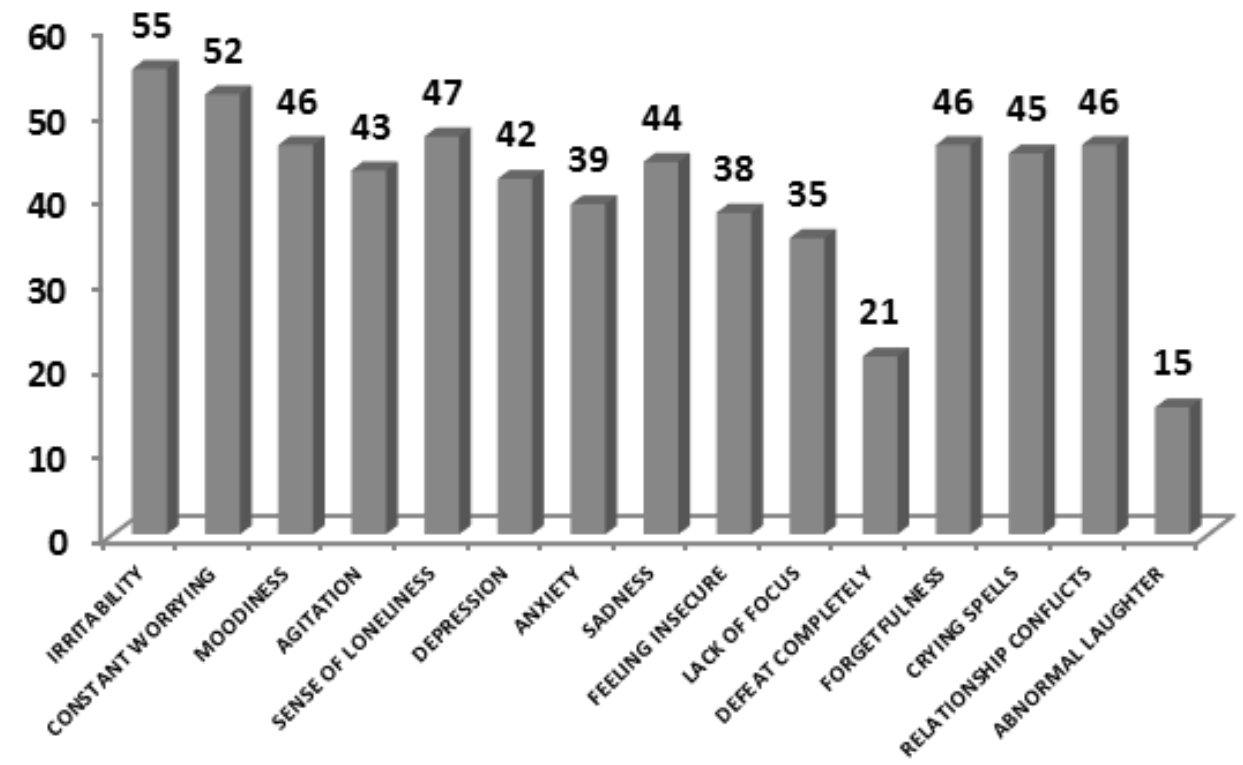

Figure 1.2: Symptoms of emotional stress

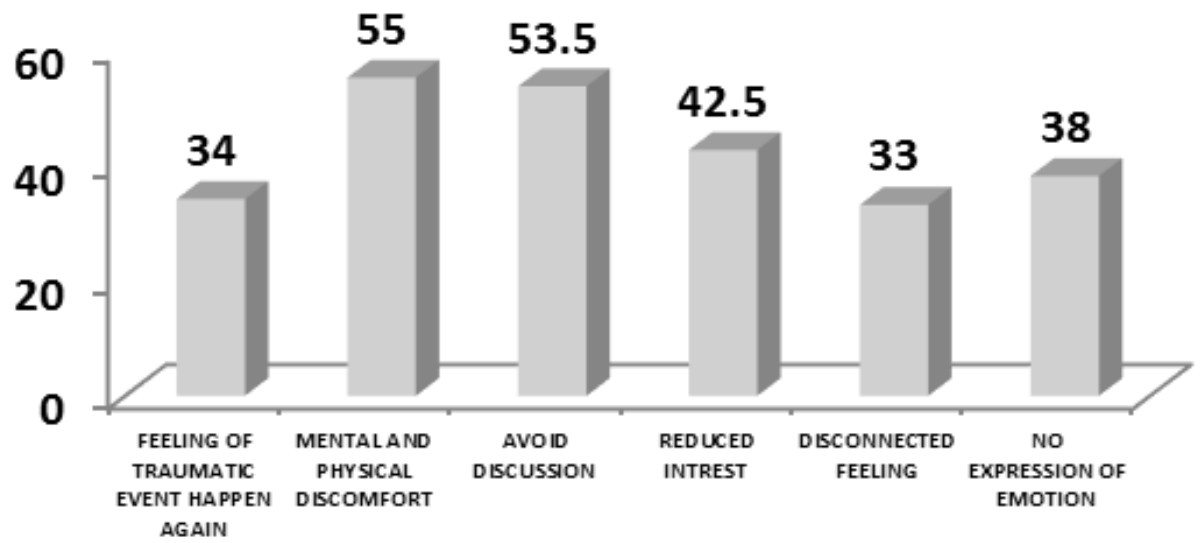

Figure 1.3: Symptoms of Traumatic Stress 


\section{Discussion}

In the Present study we found that women are suffering from excessive stress with diverse causes as $50 \%$ of the female subjects found to be emotionally stressed out. About $24 \%$ were sexually abused with most of the females reported Irritability, crying spells, sense of loneliness and depression as their symptoms of stress. Mostly they avoid discussing the traumatic event and they were afraid of reoccurrence of that event. All this may lead the victim to the edge of anxiety and may result in severe psychological issues. Both men and women are equally the victims of this type of abuse. Most of the victims were targeted by their very close ones. It is more frequently reported trauma by most of people across the world especially those areas where moral values are not followed. Current research studies showed that more $34-43 \%$ women reported emotional abuse during their childhood or adolescence. Females are not the only sufferers of emotional abuse males as well as children are also going through this insult. English, et al. 2008 found that both the parents were equally involved in verbal abuse towards their child. As stresses have a major impact on nervous system by altering and modulating its function and by creating excitotoxicity within the cells. Continuous exposure to stress or stressful ambiance can cause severe damage to memory and perception. women were sexually abused by their closed relatives and Psychologically it is believed that men are more emotionally stabled than women. So women can more easily get terrified and traumatized than men but as male usually tried to hide their grief from others and ultimately they just burst out of stress and most probably due to this reason in my survey males gave more severe results in case of traumatic stress than females is believed that women are more susceptible towards PTSDs than men. In early it was just a theory but afterwards it was proven by different scientists that it's true. Researchers have studied and came up with these results that as females and males both suffer from different traumas but females suffer more from sexual or physical assault whereas males have trauma about accidents and injuries, as female suffers from more severe and prolonged trauma that is why they are more prone to develop PTSD than males. Relevant studies suggested that patients suffering from PTSDs have higher level of pituitary adenylate cyclase-activating polypeptide (Ressler, 2016), that is found to be basis of gender differences and how more females associated with traumatized states, further studied showed genetic relationship and the found that variation in gene associated with PACAP also respond to estrogen. So this variation can also best considered as a factor of difference in the parameter of gender.

\section{Conclusion}

These variables of abuse are not only the mere threats to psychological wellbeing of victims but also have an indirect effect on their prime roles in society as a suppressed entity. Our study highlighted the causes of mistreatment, trauma, distress, outrage of frustration, Inferiority complex, Psychological disorder, Un-controllable sex desire \& Superiority syndrome. All these and all the related social constraints like cultural, religious and economic barriers the vulnerability of women to develop traumatic brains and distressed bodies.

\section{References}

- Betoule, M., Kessler, R., Guy, J., Mosher, J., Hardin, D., Biswas, R., \& Marriner, J. (2014). Improved cosmological constraints from a joint analysis of the SDSS-II and SNLS supernova samples. Astronomy \& Astrophysics, 568, A22. 
- Bremner JD., Vermetten E., Vythilingam M., et al. Neural correlates of the classic color and emotional stroop in women with abuse-related posttraumatic stress disorder. Biol Psychiatry. 2004;55:612620.

- Chan D. C., Kasper J. D., Black B. S., Rabins P. V. (2003). Presence of behavioral and psychological symptoms predicts nursing home placement in community-dwelling elders with cognitive impairment in univariate but not multivariate analysis. J. Gerontol. A Biol. Sci. Med. Sci. 58, 548-554.

- Chan W. C., Lam L. C., Tam C. W., Lui V. W., Leung G. T., Lee A., Chan S. S., Fung A. W., Chiu H. F., Chan W. M. (2011). Neuropsychiatric symptoms are associated with increased risks of progression to dementia: a 2-year prospective study of 321 Chinese older persons with mild cognitive impairment. Age Ageing 40, 30-35.

- M W Miller and N Sadeh Molecular Psychiatry 19, 1156-1162 (November 2014) | doi:10.1038/mp.2014.111 Traumatic stress, oxidative stress and post-traumatic stress disorder: neurodegeneration and the acceleratedaging hypothesis

- Miller Jr, W. M. (2014). A canticle for Leibowitz. Hachette UK.

- National Clearinghouse on Family Violence (1996). Emotional abuse.
Ottawa, Canada: Public Health Agency of Canada. OCLC 61563015. Factsheet.

- Norman, R. E., Byambaa, M., De, R., Butchart, A., Scott, J., \& Vos, T. (2012). The long-term health consequences of child physical abuse, emotional abuse, and neglect: a systematic review and metaanalysis. PLoS Med, 9(11), e1001349.

- Park, C. R., Zoladz, P. R., Conrad, C. D., Fleshner, M., \& Diamond, D. M. (2008). Acute predator stress impairs the consolidation and retrieval of hippocampus-dependent memory in male and female rats. Learning \& memory, 15(4), 271-280.

- Ressler KJ. (2016). The Intersection of Environment and the Genome in Posttraumatic Stress Disorder. JAMA Psychiatry. 1;73(7):653-4.

- Schumacher, J. A., Feldbau-Kohn, S., Slep, A. M. S., \& Heyman, R. E. (2001). Risk factors for male-to-female partner physical abuse. Aggression and violent behavior, 6(2), 281-352.

- Woolston, C. (2012). Multitasking and stress. Consumer Health Interactive, www. ahealthyme. com. Multitasking also adversely affects the brain's learning systems, which is a critical issue for Gen $M$ 's for whom multitasking is, literally, a way of life. Willis, supra and Multitasking Adversely Affects Brain's Learning, UCLA Psychologists Report, 2006-07. 